\title{
ILCEA
}

Revue de l'Institut des langues et cultures

d'Europe, Amérique, Afrique, Asie et Australie

$24 \mid 2015$

Lire et écrire ensemble

\section{Dos veces el mar}

\section{Luis Chitarroni}

\section{OpenEdition}

Journals

\section{Edición electrónica}

URL: http://journals.openedition.org/ilcea/3676

DOI: 10.4000/ilcea.3676

ISSN: 2101-0609

Editor

UGA Éditions/Université Grenoble Alpes

Edición impresa

ISBN: 978-2-84310-313-1

ISSN: 1639-6073

Referencia electrónica

Luis Chitarroni, « Dos veces el mar », ILCEA [En línea], 24 | 2015, Publicado el 02 noviembre 2015, consultado el 24 septiembre 2020. URL : http://journals.openedition.org/ilcea/3676 ; DOI : https:// doi.org/10.4000/ilcea.3676

Este documento fue generado automáticamente el 24 septiembre 2020

(C) ILCEA 


\title{
Dos veces el mar
}

\author{
Luis Chitarroni
}

1 Con el tiempo me di cuenta de que aquello que había confundido [en un principio] con cortesía, no lo era, no lo era en absoluto. Se trataba de elegancia. Y de generosidad. En cualquier caso, y si algo de cortesía quedara, habría que sacarle cualquier rezago de cortesanía, situarla en alguna de esas esencias spinozianas de las que Michel Lafon jamás hizo mención. Parte de la elegancia de Michel era una locuacidad exenta por completo de inmodestias intelectuales.

2 Nuestra amistad resultó un artículo fácil y perdurable, con Borges de por medio, aunque no recuerdo cuándo entablamos conversación con Michel la primera vez. Sí, la última vez que lo vi. Hace mucho ya, en 2009, cuando empezaba la mala racha. Mi mujer estaba internada y Michel llegó. Conocía bien a Alejandra y ambos se querían mucho. La memoria no abusa por suerte de la falta de misericordia. De Michel tengo en la cabeza una perplejidad y una obstinada incomprensión ante lo que estaba pasando, superior, incluso, a la mía.

3 El interés de Michel por la obra de Borges (y por su persona, claro) no creo que deba ponerse en contexto: cualquiera que imagine en un plano estas figuras encontrará los argumentos y motivos para trazar las flechas las afinidades electivas, las líneas o flechas que los vinculan y relacionan. Borges ou la reécriture, el primer libro de Michel sobre el tema (que antecede la traducción de La gitanilla) es un recorrido preciosamente construido. En Fragmentos de un diario de los Alpes, César Aira dice de manera enigmática que el libro de Michel es "un manual de las 'dissolving views' en la literatura". Aunque no exista en el mundo de los libros-objeto, de las "perpetual views" hubiera sido, para mí, más exacto.

4 Tengo que hablar de mi ejemplar del libro, curiosamente no dedicado. Eso se debe a que llegó a la editorial donde trabajaba, en calidad de ejemplar de prueba para una eventual publicación. Michel y yo no tuvimos suerte en estas campañas de amistad: no logré que ese libro fuera publicado por Sudamericana ni Michel que mis siluetas se tradujeran al francés en alguna de las editoriales para las que él leía. En mi caso, tuve que esperar hasta Une vie de Pierre Ménard (este sí dedicado, en el cuidado castellano lafoniano de 
Michel ("esta vida imaginaria surgida de mis nostalgias mediterráneas") para poder dar curso por fin a lo que creí un acto de justicia.

Los regalos de Michel eran tesoros verdaderos: Toulet, Schwob, el tomo primero de las Mémoires de ultratombe (solo había podido aventajar de una subasta el segundo) y, sobre todo, Maurice Renard en la edición de Bouquins. Yo soñaba que Michel nos regalaba un estudio completo de Renard, a quien conocía con tanta exactitud y dulzura, y de cuyas aventuras - de cuyas aplicadas y desplazadas aventuras- tendría tanto para decir. En más de un sentido, Renard reunía los requisitos: escritor opacado pero invencible, deslumbrante y en disfraz de secundario, siempre preciso, con una prosa toda de avances sesgados y una concentrada y sigilosa obsesión por la historia, no por el pasado. En este punto de oposición me detengo, y lo hago porque puedo redefinir cierta obsesión de Michel de la manera opuesta. Conservo sin suspenso esta presunción para retomarla más adelante.

Entre otras cosas, Michel era un eximio escritor de dedicatorias. Las encuentro en muchos libros, que me regaló con su gusto y generosidad incomparables, pero era también un virtuoso derrochador de postales, que fundan su afanosa y compleja iconografía cotidiana, imaginada por mí y observada con la distraída atención genial de César Aira. Fragmentos de un diario de los Alpes, de César, de algún modo apunta a reponer el museo, con esa lírica convicción que Michel aprovechaba en cualquier actividad imaginativa.

7 Busco el libro de Aira y, como si de azar objetivo se tratara, encuentro adentro una postal escrita por César y Michel. Efusivos, planimétricos, caligráficos, me reclaman desde Voreppe. Creo que contaban conmigo para ejercer el dominio en el que se reconoce el alto grado de lealtad que estipula la ausencia del otro como esgrima de una complicidad anterior. De la exclusión nunca considerada como un grado de expulsión.

\section{Puntualidad y puntuación: Lothar Meggendorfer. Bazelle, el vestido rosa}

8 Dentro de ese gusto por la figuración descrito en Fragmentos y compartido por Ana, la mujer de Michel, hay un placer táctil por la línea. La línea significativa y limítrofe de la ilustración, sobre todo la del dibujo de libros infantiles y los avisos publicitarios. Una cuestión había empezado [casi naturalmente] cuando Michel insistió en broma acerca de mi gusto por las malas costumbres éticas y estéticas de los ingleses y yo le dije que mi lealtad llegaba hasta Turner, de quien tenía la misma opinión que Delacroix, y a quien consideraba, junto con Rothko (copié esta opinión de Melchior de Wolf) uno de los pintores más sobrevalorados del siglo veinte. No me atreví a mencionar a Meissonier y Géricault.

9 El pasado inmediato no cobra forma de inmediato. Es una mediación, una convicción y un hábito postrero; a veces, una sustracción. Max Beerbohm se lo explica a alguno de sus interlocutores provisionales, y le da una vuelta adicional al asunto cuando postula Every man fancies a period before his own.

10 La sobrevaloración del siglo diecinueve es otro de los manierismos copiados del siglo veinte. Michel y yo teníamos el ocio suficiente para conversar sobre el tema en nuestros encuentros en el Tortoni o en largas caminatas cuyo punto de partida era la casa en San Telmo, donde él solía hospedarse. 
11 La admiración y la gratitud de Michel por sus guías e instructores era otro atributo de la lealtad (entre otros, el texto en Mélanges offerts à Maurice Molho). Alguna vez Michel me confesó cierto cansancio por la falta de recursos de la crítica. Este tipo de comentarios implicaba a menudo un silencio de su parte, de una reserva muy especial. Barthes habla de que algunos silencios de su maestro Emile Benveniste eran musicales, como los de Richter; creo que habla de silencios escritos, secreto aun más intransferible. Los silencios paralelos o análogos de Michel, orales, nada tienen en común con los de su escritura ni con su afición pianística distinta (Casadesus). En realidad, y en esa primera figuración, la semejanza se hace estrábica, y el parecido (Casadesus/Lafon) se asoma a otro binomio (Panzera/Barthes), pero la indefensión argumentativa debe en este caso recurrir a la nostalgia como única fuente, casi como epitafio.

12 Hay muchos temas que quedaron en estado de suspenso, tan larga fue nuestra conversación interrumpida. Uno fue la novela histórica, a la que Michel no parecía particularmente inclinado, pero que tenía mucho peso en su pasado, no solo en la infancia, a causa de sus múltiples intereses, entre ellos la numismática y el anacronismo (Uderzo, Goscinny).

13 Tal vez haya además un vínculo más estrecho de lo que se cree entre el arte figurativo y la novela histórica. Recuerdo la respuesta de Joyce a Beckett acerca de la historia de Inglaterra de Hume: "una historia de la representación".

14 En cualquier caso, la novela ilustrada y los niveles de operatividad de la imagen nos impulsa o impele a esa infancia atractiva en la que compartimos la edad porque compartimos la curiosidad y los intereses de la infancia, de la edad. Yo relacionaba a Michel con los protagonistas jóvenes de novelas de aventuras, como el de Antigua, Penny, Puce, de Robert Graves, o el de High Wind in Jamaica, de Richard Hughes, de modo que cuando me contó de su afición por la numismática encontré una clave más de amor por la noción de historia de las novelas de Maurice Renard (sí, rima con Ménard), que es como un paso suelto de la narrativa antes de toparse con Proust. Parecía como si Michel se hubiera arreglado, con fines artísticos, de esquivar a Proust para llegar, de pasado a historia directamente, a Borges. Para llegar directamente a Ménard.

Habíamos llegado a una conclusión provisoria (¿cuál no lo es?) acerca de la "definición” de una época. Michel fue el que aportó los datos más importantes. En parte por generosidad, se refirió a algunas características o "rasgos" de El carapálida. Dijo que hay premisas e imperativos que quien intenta establecerlas ignora, pero otros que sospecha o vislumbra. En ese caso, citaba la claridad conceptual de Borges, que decía que había que asentar los caracteres de una época de modo tal que "los rasgos circunstanciales" no dejaran de serlo; en efecto, los fanatismos esenciales quedan guardados en la cabeza de quienes "fijan" los detalles. Eso fue antes o después, se obstinan en decir. Ménard, por ejemplo, explicaba Michel, está ligeramente "corrido de época", un acto de perspicacia intelectual. Está "instalado" en una especie de "coartada" de época, que es una "edad dorada" -Valéry, Reboul, Toulet-, una época en la que el surrealismo puede ser tratado aun (por quien escribe o traduce) de "superrealismo". Es una plácida meseta artística en que las teorías de Monsieur Teste convergen o compiten con las Contrerrimes. Michel llamaba la atención acerca de que "Pierre Ménard" tiene que ser una traducción, como el Quijote: quien escribe está en el mismo nivel de lengua que el autor, no es un exégeta argentino: redactó esa noticia que apareció la primera vez en Sur, en francés (podemos jugar con la idea y no extenderla hasta la primera voz: Pepe 
Bianco traductor de Pierre Ménard autor del Quijote). No sé si tales cuestiones están planteadas ya en la La réecriture (ni me parece necesario ahora insistir ni buscarlas), pero son inherentes al tema de la novela de Michel, Une vie...

Más de una vez discutimos sobre la importancia que Borges le daba a ese cuento. Michel decía que yo exageraba cuando daba por sentado que poca porque no lo incorpora, por ejemplo, a la Antología personal de 1960 (publicada por la editorial Sur, precisamente). Yo decía que la derrocha demasiado con Bioy en las Crónicas de Bustos Domecq para seguir apreciándola y decía además que era "poca" porque Borges es un instigador supremo, un maestro de extrema severidad (que poco tiene que ver con la noción del "archididacta" de Pezzoni). Un instigador supremo da siempre una nota o una pista de menos. Cuando Borges escribe sobre la obra "visible" de Menard nada escamotea, pero dice que la traducción literal que éste hizo de la traducción literal de San Francisco de Sales que hizo Quevedo retraducida literalmente por Ménard nunca fue encontrada, y que Madame Henri Bachelier acaso no advirtió que se trataba de una broma. Del Quijote de Ménard incorpora solo un párrafo; queda el capítulo sobre las armas y las letras. Ménard discute, argumenta y no sé cuántas cosas hace hasta que el peón de la reina queda en su lugar; en la polémica con Valéry se afana todo lo posible por restituir la vieja amistad.

17 Pero estos devaneos poco intervenían en la misión de Michel, quien se disponía a instalar a Pierre Ménard en el mundo, e instalar a su vez en el mundo el de Pierre Ménard. Una misión bien diferente a la de Borges, una misión novelesca.

Creo que una biografía de PM, que consta hasta ahora como la que define el artículo indefinido, es un libro del futuro. En él están inequívocamente todos los elementos del pasado de la novela "rinden la magia que fue suya" al género.

19 Aunque hubo muchas circunstancias atenuantes, después de enterarme de la enfermedad de Michel, la correspondencia se intensificó. Siempre habíamos bromeado, sobre todo con la posibilidad de escribir libros a medias, pero creo que las convalecencias, y sobre todo los tratamientos de Michel, los pusieron al borde de la ejecución, al borde de la escritura. Todo empezó con su gusto por los policiales.

Michel se había vuelto - si es que no lo había sido toda la vida, de manera más o menos disimulada por la vida académica- de los policiales ingleses, de sus mecanismos y de sus reglas. Lo alentaba de lejos, modulando un poco la predilección con mi tendencia a la heterodoxia. Entonces descubrí las condiciones y características que implicaban escribirle un mail a una persona tan especial como Michel.

21 Los preparativos de la novela que escribiríamos fueron diferidos por un envío, por la tardanza, por el retado de un envío. Michel, fanático de John Dickson Carr, se negaba a creer, con un empecinamiento razonable y lúdico, que el peor policial que yo había leído lo hubiera escrito el propio John Dickson Carr. Y que lo hubiera firmado así, sin recurrir siquiera a Carter Dickson. Bien, en mi caso, el hecho de que fuera el peor estaba muy atenuado por otro motivo: había sido también el primero (no era estrictamente el primero, pero el que lo precedía, Estudio en escarlata, en una edición de comienzos del siglo veinte de Biblioteca La Nación titulada La mancha de sangre, por ser de Conan Doyle, permanecía fuera de la lista).

Bien, lo cierto era que Mediodía de espectros (Ghost's High Noon), a la sazón, la novela de John Dickson Carr, no resistió tampoco la lectura de Michel. 

la que descansaran nuestras preocupaciones diarias, que decidimos hacer el policial (supremo). Entonces le mandé a Michel por mail un bosquejo de la trama y un discreto elenco, como los dramatis personae de las novelas de Agatha Christie. Fue un abuso de confianza, un distante abuso de confianza de mi parte. Con elegancia impertérrita, Michel corrigió la actitud del personaje - Vernon Gish-, la vivacidad y el vestuario de su prometida -la señorita Pontifax-, la raza y el sexo de la mascota compartida (el Bedlington se convirtió en caniche en homenaje a Fiona, la perrita del hijo de Michel), y tuvo la buena conducta de objetar la época en la que se desarrollaba la acción, que yo, por una cuestión de distracción o melancolía, había ubicado a los personajes en los sesenta, un pretérito demasiado cercano. Michel dedujo esa estratagema de los autores -Gerald Kersh, Peter Cheyney, Nigel Balchin-, a quienes yo hacía contemporáneos de la víctima, a la sazón un escritor de libros exitosos.

En este caso, los escrúpulos de Michel son mucho más interesantes que mis solecismos.

El sentido de la forma y la composición remitía a sus obsesión por el policial clásico: la exposición serena, la época correspondía menos a la novela policial que a la de espionaje y las intrigas de la Guerra Fría.

Dije ya que el arte de las postales fue ejercido por Michel hasta un punto sin retorno (en gran mediada porque no era correspondido: las únicas postales que encontraba acá para enviarle eran fotos del obelisco o boleadoras y espuelas; empecé, pero después ya no pude seguir)

De las dos postales más próximas que me envió él no puedo descifrar la fecha. Fueron parte del mismo envío (cada libro traía alguna) o de la misma carta, y parecen contestar sin hacer ni siquiera referencia al tema a una inofensiva y por momentos muy jocosa discusión que sostuvimos hace mucho tiempo [en un bar de San Telmo]. A partir de la dedicatoria irónica de Borges y Bioy en Bustos Domecq ("A Picasso, Le Corbusier y Stravinsky, esos olvidados"), hablábamos de los olvidos y omisiones del siglo veinte, que a mí me parecían más graves y lesivos que a él. Había una calma muy digna de un clásico en Michel, a quien mis exageraciones lo hacían sonreír. Para buscar una inminencia que atrapara su atención, recurrí a un escritor que no sé si le gustaba (aunque sospecho que sí). "Vas a ver que este siglo va a olvidar también mucho de lo mejor que tuvo... a Raymond Queneau, por ejemplo, cuya campaña de olvido ya comenzó..." Pareció más sorprendido de que yo me valiera de un argumento tan espurio (¿quién me había transmitido el comienzo de tal campaña?) que del ejemplo mismo. "Sí, como si el olvido de Victor Hugo no fuera más grave. Cuestiones de moda", dijo. "Baudelaire y Lautréamont, por ejemplo, no son mejores poetas, pero son, en un sentido estricto, “más modernos”.' “Char y Bonnefoy son mejores que Queneau?”, me apuré en preguntar. "Tampoco mejores que Hugo, solo mejores que quienes hicieron olvidar a Hugo", me contestó. Y más tarde, cuando nos despedíamos, con su generosidad exquisita. "Hablar de Hugo y de Queneau con vos me hizo reconsiderar a Queneau... A fin de cuentas, tal vez se trate de personas parecidas, con idéntica devoción por la ciencia, y en eso no te equivoques. Tal vez Queneau haya sido un Victor Hugo sin vehemencia".

Las dos postales de las que hablé dicen (la primera): "Dos veces el mar: el de Hugo (y muestra un dibujo del mar de Hugo, que tan bien sabía hacerlo, y que tan profundamente se escapaba así y hacía huir al mar del Romanticismo escolar que le 
asignaron), y la otra (y es una foto del Mediterráneo de Gustave Le Gray), "el de Ménard, el de siempre". El mediterráneo de Ménard, el de Lafon.

28 No pudimos despedirnos como corresponde, de modo que sigo ignorando esa ceremonia; se trata sin duda de un mal menor que el acecho del azar ha vuelto indispensable. 